Cite this: New J. Chem., 2014 38, 1996

Received (in Montpellier, France) 21st August 2013. Accepted 24th October 2013

DOI: 10.1039/c3nj00972f

www.rsc.org/njc

\section{Thick titania films with hierarchical porosity assembled from ultrasmall titania nanoparticles as photoanodes for dye-sensitized solar cells}

\author{
Johann M. Feckl, Alyssa Haynes, Thomas Bein* and Dina Fattakhova-Rohlfing*
}

Thin mesoporous titania films prepared by surfactant templating feature some of the highest light conversion efficiencies per thickness ratios as anodes in dye-sensitized solar cells (DSCs). However, the fabrication of thicker films required for sufficient light absorption is very challenging using this approach, often resulting in cracking and delamination of the films. Here we present a simple and scalable method to prepare thick mesoporous titania photoanodes via a surfactant-directed assembly of crystalline ultrasmall $\mathrm{TiO}_{2}$ nanoparticles in combination with phase separation due to ethyl cellulose added to the coating solutions. Along with increasing film thickness, the ethyl cellulose introduces an interpenetrating macropore network into the films, leading to the formation of hierarchical porous films with bimodal porosity, with the smaller mesopores resulting from the structure-directing agent, Pluronic F127. In this way, films of up to $2 \mu \mathrm{m}$ per layer without delamination can be produced, exhibiting a high surface area of $130 \mathrm{~m}^{2} \mathrm{~g}^{-1}$, about twice the value of films based on standard $\mathrm{TiO}_{2}$ nanoparticle paste. The preparation of multilayer films by a sequential spin-coating and calcination procedure enables the production of films with an overall thickness of up to $10 \mu \mathrm{m}$ in only 5 steps, which showed high efficiencies of $7.7 \%$ in dye-sensitized solar cells.

\section{Introduction}

Mesoporous titania films with high surface area are highly beneficial as electrodes in photocatalysis, ${ }^{1}$ batteries $^{2}$ or dyesensitized solar cells. ${ }^{3,4}$ One of the most common techniques to prepare organized mesoporous systems is the evaporationinduced self-assembly (EISA) process in which amphiphilic polymers act as structure directing agents (SDA) for the formation of periodic nanostructures. ${ }^{5,6}$ The template is then removed by thermal decomposition, yielding porous titania films with a high surface area and an accessible pore system. Mesoporous titania morphologies with a uniform regular porosity are shown to be among the most active anodes in DSCs, demonstrating some of the highest light conversion efficiencies per thickness ratios. ${ }^{1,7-12}$ However, films prepared in an EISA process using amorphous sol-gel precursors are strongly limited in their thickness due to cracking, ${ }^{13}$ which is especially detrimental to applications involving light absorption, such as DSCs. ${ }^{14}$ This severe cracking or even delamination of films deposited as thicker coatings is caused by the large changes in density due to removal of the

Department of Chemistry and Center for NanoScience (CeNS), University of Munich (LMU), Butenandtstr. 5-13, Gerhard-Ertl-Building (E), 81377 Munich, Germany. E-mail: bein@lmu.de, dina.fattakhova@cup.lmu.de; Tel: +4989 218077621, +4989218077604 template and the crystallization and densification of the initially amorphous sol-gel precursors. Methods to overcome this challenge include multiple coating approaches where individual thin layers are coated on top of each other with intermediate calcinations to reduce the stress in the individual layers. $^{7,11,12,15}$ Therefore, this approach is very time consuming, and it only allows depositing films with about $300 \mathrm{~nm}$ thickness per cycle.

The heat-induced shrinkage of the mesoporous framework can be significantly reduced when previously prepared, therefore crystalline nanoparticles are used for the film assembly instead of amorphous precursors. However, porous networks formed by such rigid building blocks usually suffer from compromised pore periodicity and especially from inferior electrical connectivity between the nanocrystals. ${ }^{8,16}$ In a so-called 'brick and mortar' strategy, small titania nanocrystals are combined with amorphous sol-gel titania, acting as precursors for crystalline titania phases in the EISA process. ${ }^{1}$ The intimate mixing and the similar chemical composition of the nanocrystal and the sol-gel titania lead to crystallization of the amorphous precursor induced by the crystalline seeds, and allows for crystallization under mild conditions. Additionally, less shrinkage is observed during the crystallization and the densification of the material, leading to films of typically about $700 \mathrm{~nm}$ thickness. Although the 'brick and mortar' films can be made 
much thicker than the sol-gel based films, the thickness of the films obtained in one coating and thus the effective surface area are still not sufficient for high performance electrodes in DSCs. Thicker films can again be made by stacking multiple layers of porous titania on top of each other by a sequential coating and calcination process. ${ }^{17}$ In contrast to the sol-gel films whose porous morphology deteriorates after a few subsequent coatings, the porosity and surface area of the 'brick and mortar' films scale up linearly with the number of coatings. However, a desirable thickness of about $10 \mu \mathrm{m}$ still requires up to 15 time-consuming subsequent coatings followed by intermediate calcination steps.

Here we have developed a method to fabricate thick mesoporous 'brick and mortar' titania coatings in a simple way, which could make this promising morphology more suitable for large-scale applications. One of the key approaches to increase the film thickness and with it the efficiency is the addition of ethyl cellulose to a modified coating solution containing the surfactant Pluronic F127. The ethylcellulose acts as a thickener increasing the viscosity of the coating solutions and enabling fabrication of approximately $2 \mu \mathrm{m}$ thick layers after calcination in a single coating step. Furthermore, the ethyl cellulose leads to the formation of macropores in addition to the mesopores due to a phase separation effect also observed by other authors for these high molecular weight additives. ${ }^{18-22}$ The thick films obtained in this way have a hierarchical pore system that can be described as a bimodal mesoporousmacroporous system with interpenetrating macropores. The preparation of multilayer films by a sequential spin-coating and calcination procedure enables the production of films with an overall thickness of up to $10 \mu \mathrm{m}$ in only 5 steps. In this way, it was possible to increase the photo-conversion efficiency of resulting photovoltaic devices by a factor of 2.5 compared to a single layer and to obtain efficiencies comparable to the 15 layer $(10 \mu \mathrm{m})$ brick and mortar films.

\section{Results and discussion}

Ultra-small titania nanoparticles were synthesized as described in a previous study. ${ }^{2}$ The $3 \mathrm{~nm}$ sized crystalline titania nanoparticles are perfectly dispersed in the reaction solution and non-agglomerated. In this way the as-prepared solutions can be directly utilized for the preparation of mesostructured films via spin-coating on conductive transparent oxide coated glass substrates after adding a structure directing agent such as the triblock copolymer Pluronic P123. The titania content of the resulting solution is about $27 \mathrm{mg} \mathrm{TiO}_{2}$ per $\mathrm{mL}$ solvent (3.5 wt\%) if a $100 \%$ reaction yield is assumed. The films are calcined at $450{ }^{\circ} \mathrm{C}$ to remove the template and fully crystallize the scaffold. This procedure is very simple, but leads to individual layers of only around $300 \mathrm{~nm}$ thickness after calcination. This is due to a limited concentration of the nanoparticles in the as-prepared synthesis solution, as the ultra-small titania nanoparticles are obtained only at certain precursor concentrations. To increase the concentration of nanoparticles, the dispersion was concentrated

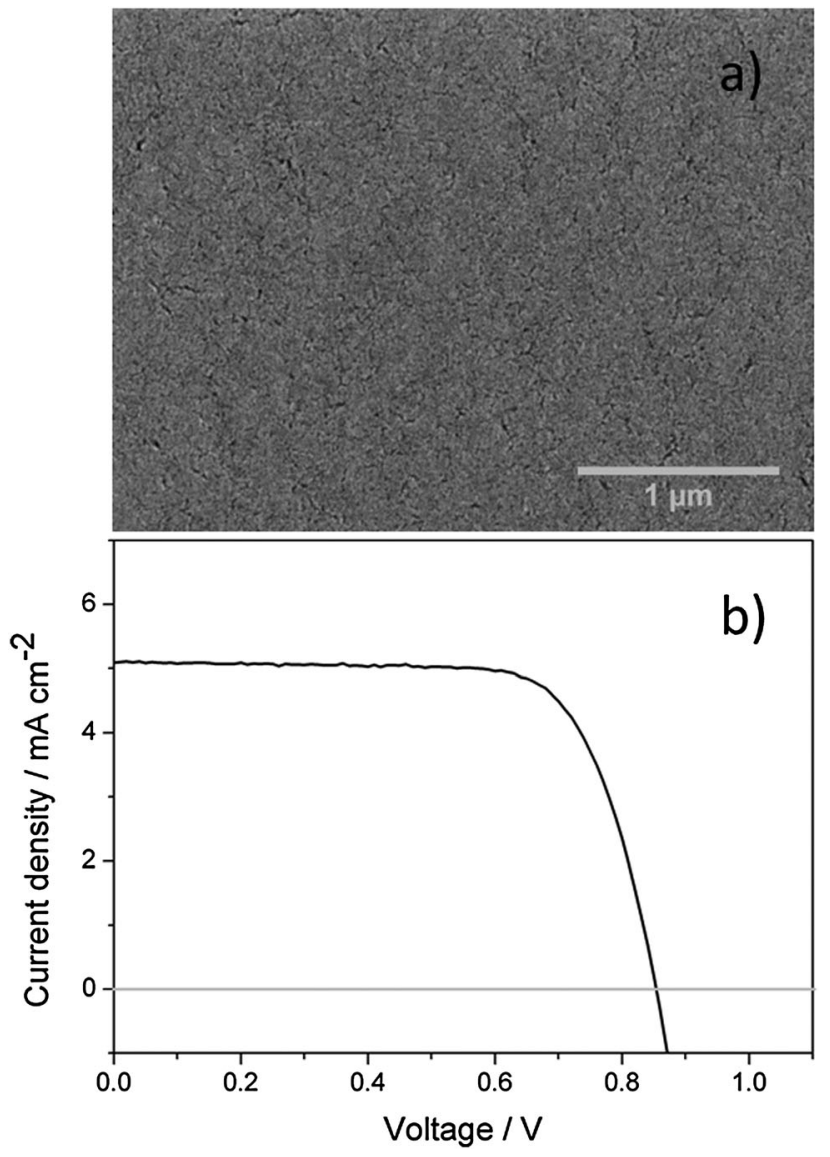

Fig. 1 (a) Top-view SEM image of a $700 \mathrm{~nm}$ thin mesoporous titania film prepared from a concentrated solution of ultra-small titania nanoparticles and calcined at $450{ }^{\circ} \mathrm{C}$. (b) Photocurrent-voltage curve of a DSC constructed with the film shown in the SEM image, an N719 sensitizer and a volatile $\mathrm{I}^{-} / \mathrm{I}_{3}{ }^{-}$electrolyte. The photovoltaic performance was measured at air mass $1.5\left(100 \mathrm{~mW} \mathrm{~cm}^{-2}\right)$ full sunlight illumination. The active cell area was $0.196 \mathrm{~cm}^{2}$.

by evaporating around $40 \%$ of the initial solvent volume, thus leading to a titania content of about $45 \mathrm{mg} \mathrm{TiO}_{2}$ per $\mathrm{mL}$ solvent (5.8 wt\%) of the resulting solution. Films prepared with this concentrated solution exhibit a film thickness of around $700 \mathrm{~nm}$ after calcination, as determined by profilometry. The films are transparent and the worm-like porous system is highly accessible from the surface as depicted in the SEM image in Fig. 1a. The application of such a film as a photoanode in a DSC with N719 as a sensitizer ${ }^{23}$ leads to a very high photo-conversion efficiency of $3.2 \%$ for such a thin film (Fig. 1b). Additionally, the open circuit voltage of $850 \mathrm{mV}$ is relatively high compared to other films prepared from slightly bigger nanoparticles synthesized in benzyl alcohol. ${ }^{17}$ This could be due to different surface compositions of the nanoparticles, as in the latter case the products of the non-complete combustion of aromatic benzyl alcohol groups could remain on the surface even after calcination. Additionally, the minute size of the ultra-small nanoparticles could lead to better sintering of the particles upon calcination in the mesostructure and therefore to enhanced electronic properties of the resulting films. 

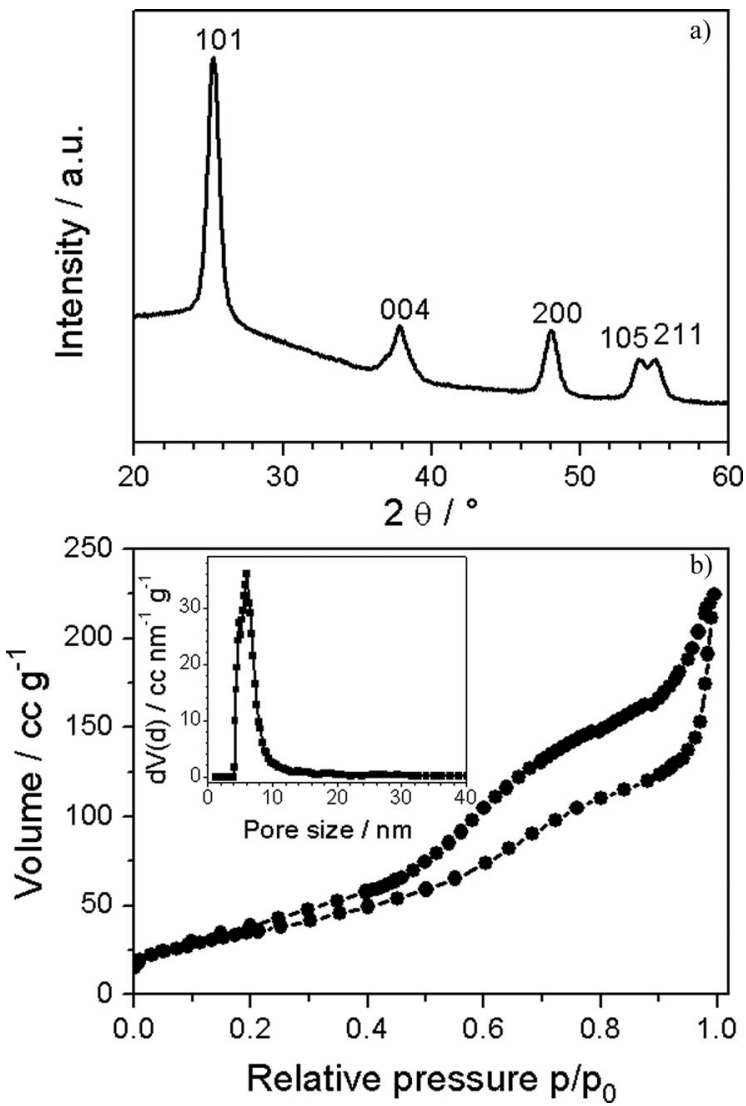

Fig. 2 (a) XRD pattern of anatase material obtained from films calcined at $425^{\circ} \mathrm{C}$. The average crystallite size was determined to be $10 \mathrm{~nm}$ calculated using the Scherrer equation from the broadening of the 101 reflection. (b) Nitrogen sorption isotherm of a scratched-off powder from 3-layer films prepared with ethyl cellulose. The inset shows the corresponding DFT pore size distribution.

Powder X-ray diffraction (XRD) patterns of scratched off films that had been calcined at $425{ }^{\circ} \mathrm{C}$ show pure anatase with a crystallite size calculated from the peak broadening of the 101 reflection to be $10 \mathrm{~nm}$ (Fig. 2a). Compared to the initial size of the crystallites of $3 \mathrm{~nm}$ this accounts for a growth of $340 \%$ indicating a good interconnection of the mesoporous scaffold. The obtained high short circuit current of $5.09 \mathrm{~mA} \mathrm{~cm} \mathrm{~cm}^{-2}$ compared to the film thickness of only $700 \mathrm{~nm}$ can be attributed to the high surface area of the film which is proportional to the dye loading and therefore the generated current (Fig. 1b). The fill factor of $73.8 \%$ is in a usual range for this type of DSC.

In order to achieve higher efficiencies, a procedure to obtain films with increased thickness was developed, in which the coating solution had to be prepared in a different way compared to the procedure described above for the $700 \mathrm{~nm}$ film. First of all, the ultra-small titania nanoparticles were separated from the reaction solution by flocculation with the apolar solvent heptane (2:1 heptane: reaction solution) and subsequent centrifugation. The obtained pellet was quickly redispersed in absolute ethanol and the surfactant Pluronic F127 was added and dissolved under stirring and heating at $60{ }^{\circ} \mathrm{C}$. Afterwards a 10 weight\% solution of ethyl cellulose was added
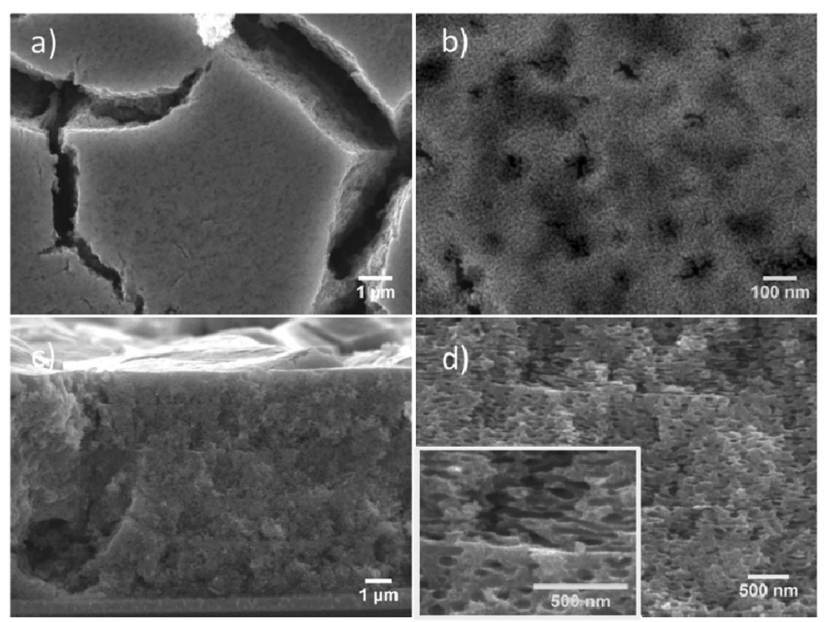

Fig. 3 Top-view SEM images of a $8 \mu \mathrm{m}$ 4-layer titania film prepared with the addition of ethyl cellulose and calcined at $425^{\circ} \mathrm{C}(\mathrm{a}, \mathrm{b})$. Cross-sectional images of the films (c, d). The ethyl cellulose-derived pores are visible in the inset in (d).

and the resulting solution was used for spin-coating to produce films of up to $2 \mu \mathrm{m}$ thickness after calcination at $425{ }^{\circ} \mathrm{C}$. This increase in film thickness per layer is attributed to the higher viscosity of the coating solution after the addition of ethyl cellulose and the increased titania content of the dispersion (107 $\mathrm{mg} \mathrm{TiO}_{2}$ per $\mathrm{mL}$ solvent, $13.6 \mathrm{wt} \%$ ) by over a factor of 2 compared to the concentrated solution without ethyl cellulose. This leads to a higher amount of titania remaining on the substrate during the spin-coating process. The addition of ethyl cellulose also causes a morphological change compared to films prepared without it. In addition to the small pores formed from the template Pluronic F127, bigger pores of over $60 \mathrm{~nm}$ produced from ethyl cellulose can be observed (Fig. 3).

The cross-sectional SEM image shows a homogeneous distribution of the smaller and bigger pores throughout the whole film, resulting in a bimodal pore system with pores of around 6-8 nm resulting from the template Pluronic F127, and pores of around 60-100 $\mathrm{nm}$ from the ethyl cellulose (Fig. 3c and d). This bimodal pore system with its bigger pores from the ethyl cellulose can be advantageous for electrolyte diffusion resulting in good mobilities and possibly less recombination. The cracks perpendicular to the FTO substrate are only present in the top layer which was applied in the last coating, because during the preparation of multiple layers they are filled up with new material. These cracks could also be advantageous channels for a fast mass transport in the electrolyte, especially combined with the large pore system of the ethyl cellulose that connects the smaller pores resulting from the F127 template. In this way, a high surface area of $130 \mathrm{~m}^{2} \mathrm{~g}^{-1}$ is successfully combined with an accessible pore system with a pore size distribution of around $6 \mathrm{~nm}$ (Fig. 2b). For the preparation of thicker films, the complete procedure of film formation was repeated with fresh coating solutions until the desired film thickness was obtained. The evolution of film thickness follows a linear trend as depicted in Fig. 4b, flattening off for higher film thicknesses. Films prepared in this way are not completely crack-free (Fig. 3a) 


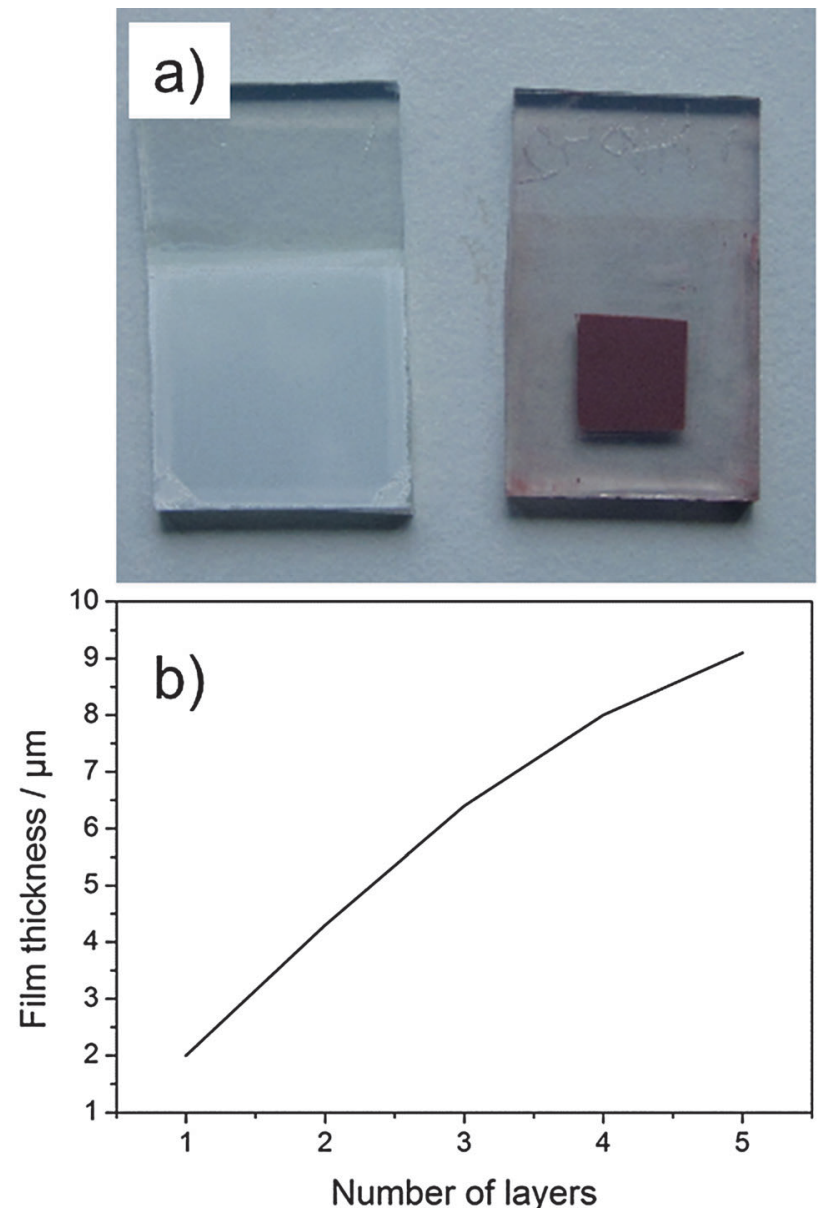

Fig. 4 (a) Image of films prepared with ethyl cellulose after calcination at $425^{\circ} \mathrm{C}$ (left) and after immersion of the partially scratched film in the dyesolution for 3 days (right). (b) Evolution of film thickness of multi-layered films prepared with ethyl cellulose and intermediate calcination steps at $425^{\circ} \mathrm{C}$.

and therefore appear to be light-scattering and white, but look homogeneous, are stable and do not peel off the substrates (Fig. 4a).

The photograph of the film which was reduced to a suitable size (by scratching) for the manufacturing of DSCs and immersed in a solution of N719 dye for 3 days displays intense color indicating a desirable high light absorption caused by the high surface area and therefore the high dye adsorption capability of these films (Fig. 4a).

Since the current injected into the titania scaffold is approximately proportional to the dye loading, it can explain the trend of the increasing short circuit current for increasing film thickness (Fig. 5b). The decline in photocurrent for very thick films can be ascribed to a higher recombination in thicker films since the pathways for the electrons are longer. In the same way, the power conversion efficiency rises up to $7.7 \%$ for a thickness of $8.0 \mu \mathrm{m}$ and drops off for even thicker films (Fig. 5). The maximum can be explained by an optimum in both light absorption (resulting from a combination of high surface area and sufficient film thickness) and efficient charge extraction. Additionally, all samples show a high open circuit potential for this system of up to $874 \mathrm{mV}$. These observations are attributed

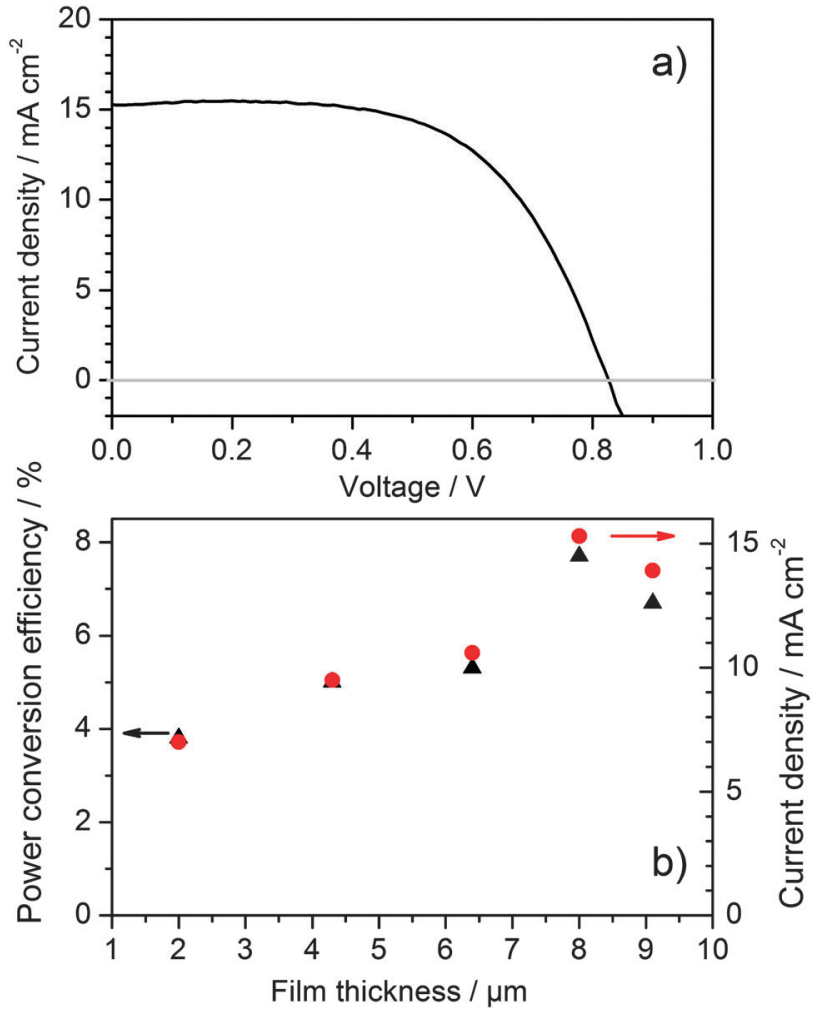

Fig. 5 (a) Photocurrent-voltage curve of the best-performing DSC constructed with an $8 \mu \mathrm{m}$ thick film prepared with ethyl cellulose, multi-layering, a N719 sensitizer and a volatile $\mathrm{I}^{-} / \mathrm{I}_{3}^{-}$electrolyte. The photovoltaic performance was measured at air mass $1.5\left(100 \mathrm{~mW} \mathrm{~cm}^{-2}\right)$ full sunlight illumination. The active cell area was $0.196 \mathrm{~cm}^{2}$. (b) Power conversion efficiency (black triangles) and current density at short circuit conditions (red circles) depending on the thickness of the films prepared with ethyl cellulose.

Table 1 Photovoltaic performance of DSCs made using Pluronic F127 and ethyl cellulose templated mesoporous $\mathrm{TiO}_{2}$ electrodes with varying thickness, and employing the N719 dye with a volatile electrolyte under 1 sun illumination

\begin{tabular}{llllll}
\hline $\begin{array}{l}\text { Number } \\
\text { of layers }\end{array}$ & $\begin{array}{l}\text { Thickness } \\
{[\mu \mathrm{m}]}\end{array}$ & $\begin{array}{l}V_{\mathrm{OC}} \\
{[\mathrm{mV}]}\end{array}$ & $\begin{array}{l}I_{\mathrm{SC}} \\
{\left[\mathrm{mA} \mathrm{cm}{ }^{-2}\right]}\end{array}$ & $\begin{array}{l}\mathrm{FF} \\
{[\%]}\end{array}$ & $\begin{array}{l}\text { Efficiency } \\
{[\%]}\end{array}$ \\
\hline 1 & 2.0 & 874 & 7.0 & 61.0 & 3.8 \\
2 & 3.9 & 812 & 9.1 & 61.2 & 4.5 \\
2 & 4.3 & 838 & 9.5 & 62.4 & 5.0 \\
3 & 5.4 & 795 & 9.7 & 62.0 & 4.8 \\
3 & 6.4 & 795 & 10.6 & 62.3 & 5.3 \\
4 & 8.0 & 827 & 15.3 & 60.7 & 7.7 \\
4 & 8.3 & 862 & 14.3 & 61.2 & 7.5 \\
5 & 9.0 & 852 & 12.2 & 59.4 & 6.2 \\
5 & 9.1 & 852 & 13.9 & 56.5 & 6.7 \\
\hline
\end{tabular}

to the high accessibility of the thin-walled bimodal pore system and the crystallinity of the films. The characteristics of the solar cells are summarized in Table 1.

\section{Conclusion}

In conclusion, this study shows an efficient method for the preparation of mesoporous titania films from preformed ultra-small 
titania nanoparticles as electrodes for dye-sensitized solar cells. The addition of ethyl cellulose to the spin-coating solution leads to the formation of films with around $2 \mu \mathrm{m}$ thickness per single layer and exhibits a bimodal pore system induced by the structure-directing agent Pluronic F127 and ethyl cellulose. A multi-layering technique allows for preparing mesoporous films of up to $10 \mu \mathrm{m}$ in a short time and few steps. Concerning the application of the films in DSCs, it was found that the efficiency rises for increasing film thickness and reaches a maximum of $7.7 \%$ at around $8 \mu \mathrm{m}$. These high performing mesoporous films would also be attractive candidates for application as photoanodes in other types of solar cells with alternative hole conductors.

\section{Experimental}

\section{Fabrication and characterization of titania films}

Ultra-small titania nanoparticles were synthesized using a tertbutanol microwave procedure. ${ }^{2}$ Titanium tetrachloride $(0.7 \mathrm{~mL}$, $6.9 \mathrm{mmol}$ ) was added to dry toluene $(5 \mathrm{~mL})$ under stirring in a $10 \mathrm{~mL}$ glass vial. The resulting orange solution was added under stirring to dry tert-butanol $(15 \mathrm{~mL})$ in a $20 \mathrm{~mL}$ glass vial, which formed a yellow solution. The tert-butanol was dried over 4 A molecular sieves at $28{ }^{\circ} \mathrm{C}$ and filtered through a syringe filter prior to use. The mixture was then heated with microwave radiation to $80{ }^{\circ} \mathrm{C}$ for 1 minute and then held at $50{ }^{\circ} \mathrm{C}$ for 20 min (Synthos 3000, Anton Paar). After cooling to room temperature, the same microwave procedure was repeated 20 hours later to complete the NP synthesis, yielding a very faint yellow, transparent solution.

For the preparation of the $700 \mathrm{~nm}$ film, $4 \mathrm{~mL}$ of the as-prepared nanoparticle dispersion as described above was added to $0.132 \mathrm{~g}$ Pluronic P123 and this solution was kept at room temperature for $24 \mathrm{~h}$ to remove approximately $40 \%$ of the solvent tert-butanol. This concentrated solution was then used for spin-coating at $2000 \mathrm{rpm}$ for $30 \mathrm{~s}$ by applying $120 \mu \mathrm{L}$ of this solution onto the Scotch-tape masked FTO coated glass substrates (TEC-7 from Pilkington) with a sintered coating $(\sim 70 \mathrm{~nm})$ of a TEOT blocking layer, leaving a $1.5 \times 1.5 \mathrm{~cm}^{2}$ accessible surface.

For the preparation of thicker films, the nanoparticles were separated from the reaction solution by flocculation with the apolar solvent $n$-heptane (2:1 heptane:reaction solution) and subsequent centrifugation at $20500 \mathrm{rpm}$ (49000 ref) for 20 minutes (Sorvall Evolution RC, Thermo Scientific). The obtained pellet was quickly redispersed in absolute ethanol in the ratio of $0.3 \mathrm{~g}$ nanoparticles per $1 \mathrm{~mL}$ ethanol. To this dispersion, $0.07 \mathrm{~g}$ per $\mathrm{mL}$ of the surfactant Pluronic F127 in ethanol was added and dissolved under stirring and heating to $60{ }^{\circ} \mathrm{C}$ for several minutes in a drying oven. Afterwards $0.4 \mathrm{~mL}: 1 \mathrm{~mL}$ of a 10 weight $\%$ solution of ethyl cellulose in ethanol was added and $120 \mu \mathrm{L}$ of the solution was used for spin-coating at $800 \mathrm{rpm}$ for $30 \mathrm{~s}$ as described above. The resulting films were calcined at $425{ }^{\circ} \mathrm{C}$ (with a ramp of $0.6{ }^{\circ} \mathrm{C} \mathrm{min}^{-1}$ ) for 30 minutes in a laboratory oven.
For the analysis of the surface area of the samples, the calcined films were removed from the substrates and from the resulting powders sorption isotherms of $\mathrm{N}_{2}$ at the boiling point of liquid nitrogen (approx. $77 \mathrm{~K}$ ) were recorded using a Quantachrome Autosorb-1. Samples were degassed for $12 \mathrm{~h}$ at $150{ }^{\circ} \mathrm{C}$ under vacuum of turbo- and diaphragm pumps. The pore size distribution was calculated from the adsorption branch using the NLDFT adsorption branch model for silica, with cylindrical pores.

\section{Assembly and characterization of DSCs}

The sintered films were scratched off of the edges of the glass so that only a square in the middle with sides slightly larger than $0.5 \mathrm{~cm}$ in length remained. This was done to reduce both lateral electron percolation and the amount of dye adsorbed on film not used in the DSC. The films were then cleaned from water and organics by heating on a hot plate for $30 \mathrm{~min}$ at $120{ }^{\circ} \mathrm{C}$ under two UV lamps (254 $\mathrm{nm}$ and $\left.365 \mathrm{~nm}\right)$. The films were completely immersed in the ruthenium-based polypyridyl dye, N719 $(0.592 \mathrm{mg})$, in a $1: 1$ ratio of acetonitrile : tert-butanol solution $(1 \mathrm{~mL})$ for 3 days.

To create the blocking layer solution, concentrated $\mathrm{HCl}$ $(0.37 \mathrm{~mL}, 4.4 \mathrm{mmol})$ and TEOT $(0.55 \mathrm{~mL}, 2.6 \mathrm{mmol})$ were added in a $10 \mathrm{~mL}$ glass vial. THF $(7 \mathrm{~mL})$ was then added, and the solution was stirred for at least $5 \mathrm{~min}$. FTO-coated glass was cleaned for $15 \mathrm{~min}$ by ultrasonication in a 1:1 solution of ethanol:acetone. The glass was wiped with a laboratory wiper (Kimwipes, Kimberly-Clark) and then plasma cleaned in oxygen plasma for $5 \mathrm{~min}$ at $50 \%$ power to remove the remaining organic residues (Femto UHP, Diener Electronic). The blocking layer solution was spin coated onto the FTO glass at $4000 \mathrm{rpm}$ for $30 \mathrm{~s}$. The coated glass was sintered with a ramp of 11 hours to $450{ }^{\circ} \mathrm{C}$, holding this temperature for $30 \mathrm{~min}$. The above porous titania layers were coated on top of the blocking layer just described.

The counter electrodes were prepared by first drilling a $1 \mathrm{~mm}$ hole into FTO coated glass. The glass was then cleaned by ultrasonication for $15 \mathrm{~min}$ in a $1: 1$ solution of water: ethanol and a drop of soap. After rinsing in ethanol, the drilled glass was ultrasonicated twice for 15 minutes in ethanol. The counter electrodes were wiped with a laboratory wiper (Kimwipes, Kimberly-Clark) and then plasma cleaned for $5 \mathrm{~min}$ at $50 \%$ power to remove the remaining organic residues (Femto UHP, Diener Electronic). The Pt catalyst was applied by spreading a drop of a solution of $\mathrm{H}_{2} \mathrm{PtCl}_{6}(2 \mathrm{mg}, 4.8 \mu \mathrm{mol})$ in ethanol $(1 \mathrm{~mL})$. The Pt-coated glass was slowly heated on a hot plate to $400{ }^{\circ} \mathrm{C}$ in increments of $50{ }^{\circ} \mathrm{C}$ every $10 \mathrm{~min}$.

The electrolyte solution was prepared by mixing together 1-butyl-3-methylimidazolium iodide $(0.536 \mathrm{~mL}, 60 \mathrm{mmol})$, iodine $(0.038 \mathrm{~g}, 1.5 \mathrm{mmol})$, guanidinium thiocyanate $(0.059 \mathrm{~g}$, $10 \mathrm{mmol})$, 4-tert-butylpyridine $(0.37 \mathrm{~mL}, 50 \mathrm{mmol})$, acetonitrile $(4.25 \mathrm{~mL})$, and valeronitrile $(0.75 \mathrm{~mL})$ in a $20 \mathrm{~mL}$ glass vial.

For the assembly of DSCs, the films were removed from the dye solution and rinsed with acetonitrile. A $60 \mu \mathrm{m}$ surlyn plastic insert with a $0.196 \mathrm{~cm}^{2}$ hole was sandwiched between the mesoporous film electrode and the platinum-covered counter electrode. 
The DSC was placed on a hot plate at $150{ }^{\circ} \mathrm{C}$ for $30 \mathrm{~s}$ to melt the plastic enough to adhere the two electrodes together. The electrolyte was then injected into the DSC by vacuum backfilling through a pre-drilled hole in the counter electrode. After the hole in the plastic insert was completely filled with the electrolyte, the DSC was sealed with tape. The outside of the DSC was cleaned with ethanol to complete the assembly.

The photovoltaic characterization of solar cells was performed on an AM 1.5 solar simulator (Solar Light Co.). The measurements were conducted under one sun illumination, and the light intensity was monitored using a pyranometer (PMA2100, Solar Light Co.). Current density-voltage measurements were performed using a Zahner IM6ex impedance measurement unit.

\section{Acknowledgements}

Financial support from the DFG (SPP 1613), the NIM cluster (DFG), the research network 'Solar Technologies Go Hybrid' (State of Bavaria), the Center for NanoScience (CeNS), and LMU mentoring is gratefully acknowledged. A. H. is grateful to the National Science Foundation (CHE-0755206) and the RISE program (DAAD) for the scholarship.

\section{Notes and references}

1 J. M. Szeifert, D. Fattakhova-Rohlfing, D. Georgiadou, V. Kalousek, J. Rathouský, D. Kuang, S. Wenger, S. M. Zakeeruddin, M. Grätzel and T. Bein, Chem. Mater., 2009, 21, 1260-1265.

2 J. M. Szeifert, J. M. Feckl, D. Fattakhova-Rohlfing, Y. Liu, V. Kalousek, J. Rathousky and T. Bein, J. Am. Chem. Soc., 2010, 132, 12605-12611.

3 B. O'Regan and M. Gratzel, Nature, 1991, 353, 737-740.

4 X. Chen and S. S. Mao, Chem. Rev., 2007, 107, 2891-2959.

5 C. J. Brinker, Y. Lu, A. Sellinger and H. Fan, Adv. Mater., 1999, 11, 579-585.

6 C. Sanchez, C. Boissière, D. Grosso, C. Laberty and L. Nicole, Chem. Mater., 2008, 20, 682-737.
7 M. Zukalová, A. Zukal, L. Kavan, M. K. Nazeeruddin, P. Liska and M. Grätzel, Nano Lett., 2005, 5, 1789-1792.

8 S. H. Ahn, W. S. Chi, J. T. Park, J. K. Koh, D. K. Roh and J. H. Kim, Adv. Mater., 2012, 24, 519-522.

9 K. Hou, B. Tian, F. Li, Z. Bian, D. Zhao and C. Huang, J. Mater. Chem., 2005, 15, 2414-2420.

10 E. Lancelle-Beltran, P. Prené, C. Boscher, P. Belleville, P. Buvat, S. Lambert, F. Guillet, C. Boissiere, D. Grosso and C. Sanchez, Chem. Mater., 2006, 18, 6152-6156.

11 J. Tao, Y. Sun, M. Ge, X. Chen and N. Dai, ACS Appl. Mater. Interfaces, 2009, 2, 265-269.

12 Y. Zhang, Z. Xie and J. Wang, ACS Appl. Mater. Interfaces, 2009, 1, 2789-2795.

13 J. Procházka, L. Kavan, V. Shklover, M. Zukalová, O. Frank, M. Kalbáč, A. Zukal, H. Pelouchová, P. Janda and K. Mocek, Chem. Mater., 2008, 20, 2985-2993.

14 A. Hagfeldt, G. Boschloo, L. Sun, L. Kloo and H. Pettersson, Chem. Rev., 2010, 110, 6595-6663.

15 M. Zukalová, J. Procházka, A. Zukal, J. H. Yum and L. Kavan, Inorg. Chim. Acta, 2008, 361, 656-662.

16 P. Hartmann, D.-K. Lee, B. M. Smarsly and J. Janek, ACS Nano, 2010, 4, 3147-3154.

17 J. M. Szeifert, D. Fattakhova-Rohlfing, J. Rathouský and T. Bein, Chem. Mater., 2012, 24, 659-663.

18 S. Ito, S. Yoshida and T. Watanabe, Bull. Chem. Soc. Jpn., 2000, 73, 1933-1938.

19 T. T. T. Pham, T. Bessho, N. Mathews, S. M. Zakeeruddin, Y. M. Lam, S. Mhaisalkar and M. Grätzel, J. Mater. Chem., 2012, 22, 16201-16204.

20 S. Bu, Z. Jin, X. Liu, T. Yin and Z. Cheng, J. Mater. Sci., 2006, 41, 2067-2073.

21 G. L. Drisko, A. Zelcer, X. Wang, R. A. Caruso and G. J. d. A. Soler-Illia, ACS Appl. Mater. Interfaces, 2012, 4, 4123-4130.

22 J. Konishi, K. Fujita, K. Nakanishi and K. Hirao, Chem. Mater., 2006, 18, 6069-6074.

23 M. K. Nazeeruddin, A. Kay, I. Rodicio, R. Humphry-Baker, E. Mueller, P. Liska, N. Vlachopoulos and M. Graetzel, J. Am. Chem. Soc., 1993, 115, 6382-6390. 